\title{
Synchronization of Oestrus in Marwari Mares Using Different Hormonal Protocols During the Breeding Season
}

\author{
Jugraj Singh Mahal, Harmeet Singh Sandhu and Touqeer Ahmed* \\ Department of Veterinary Gynecology and Obstetrics, Khalsa College of Veterinary and Animal Sciences, Amritsar, \\ Punjab, INDIA \\ "Corresponding author: T Ahmed; E-mail: touqeertaz@gmail.com
}

Received: 26 May, 2021

Revised: 01 June, 2021

Accepted: 02 June, 2021

\begin{abstract}
This experiment was performed to access the effect of different hormonal protocols during breeding season of mares (March to August) in Punjab. A total of 25 Marwari mares with regular oestrous cycle were selected betweenage group of 4-12 years and divided randomly into 3 groups. Group $1(\mathrm{n}=10)$ mares were treated with Estrumate (PG) and Chorulon (HcG) based protocol. The ovarian status of each mare was detected by ultrasonography. Mares having mature corpus luteum (CL) and medium size $(20 \mathrm{~mm}-24 \mathrm{~mm}$ ) growing follicle (day 1) were injected with Estrumate (cloprostanol sodium $500 \mu \mathrm{g}) 2 \mathrm{ml}$ intramuscularly on day 1 morning and then on morning of $6^{\text {th }}$ day injection Chorulon (3000 I.U.) was administered intravenously. On day 14 mares were again injected with Estrumate $2 \mathrm{ml}$ intramuscularly followed by injection chorulon 3000 I.U. intravenously on $20^{\text {th }}$ day morning. In group $2(\mathrm{n}=10)$ mares were injected with single injection of Estrumate $2 \mathrm{ml}$ intramuscularly after detection of mature $\mathrm{CL}$ and medium size growing follicles $(20-24 \mathrm{~mm})$. In group $3(\mathrm{n}=5)$ all mares were covered during natural oestrus. Mares in all groups were covered twice at 36 hours interval after detection of dominant follicle ( $\geq 30 \mathrm{~mm}$ diameter), clinical oestrus signs and teasing score. The conception rates were 70\% (7/10), 60\% (6/10) and 60\% (3/5) in Group 1, 2 and 3 respectively. Mares of group 1 had better pregnancy rate than other groups hence it was concluded that exogenous administration of hormones for oestrus synchronization in Marwari mares was quite beneficial and also reduced the rearing cost of the stud farmers.
\end{abstract}

\section{HIGHLIGHTS}

(0 Unawareness among breeders for synchronization of oestrus by using different hormonal regimens results in increased incidence of various reproductive disorders.

(0 The conception rate was best in the group treated with PG and $\mathrm{HcG}$ based protocol.

( The use to exogenous hormones is quite helpful in synchronization of estrus and timely ovulation in mares which increases the chances of conception during breeding season.

Keywords: Marwari Mares, Oestrus Synchronization, Hormonal protocol, Ultrasonography, Teasing

In tropical conditions particularly India as the day length starts increasing (photoperiod) mares start returning to their normal cyclicity of oestrous. Mares come under the category of long day breeders among the seasonally breeding animals and breeding season goes around its peak when day length reach up to 13-14 hours (March to August). During the peak breeding season the ovaries become large in size (3-5 $\mathrm{cm}$ in diameter), soft and active. The Pineal gland is solely responsible for stimulation of oestrous cycle which is sensitive to increasing day length intensity (photoperoid) either natural or artificial. As the day length (photoperiod) increases it leads to reduction in melatonin secretion as a result hypothalamus gets stimulated to secrete gonadotrophins releasing hormone $(\mathrm{GnRH})$. Which is further responsible for releasing

How to cite this article: Mahal, J.S., Singh, Sandhu, H.S. and Ahmed, T. (2021). Synchronization of Oestrus in Marwari Mares Using Different Hormonal Protocols During the Breeding Season. J. Anim. Res., 11(04) 669-673.

Source of Support: None; Conflict of Interest: None क क 
sufficient FSH and LH from anterior pituitary (Vidauri et al., 2018) and mares turns to normal cyclicity during the breeding season.

During the breeding season mares are having regular oestrous cycles of 21 days (McCue, 2010) that is dissimilar to the transition period (September - November) as the day length starts decreasing which may leads to irregular consecutive oestrous cycles. During the transition period only a few mares show oestrus signs with prolonged oestrus length, follicles may decrease in size and regress without ovulation. Therefore, conception rates are very low during transitional period (Sertich, 2020). Finally, after the transition period then mares enter into anestrous period (December-February). This period leads to the alternation of ovarian function which turns from maximal activity to reproductive inactivity. During this period of day length around 8-9 hours, the ovaries become reproductively inactive, small $(1-1.5 \mathrm{~cm})$ and smooth and there are no signs of estrus. Application of exogenous hormones for oestrus synchronization in Marwari mares is very rare in India. Unawareness among breeders for synchronization of oestrus by using different hormonal regimens results in increasing incidence of various reproductive disorders like prolonged and irregular oestrus length, anovulation and conception failure.

\section{MATERIALS AND METHODS}

The 25 Marwari mares of age group between 3-12 years and having BCS (Body condition score) 5/9 (Evans, 2010) with regular oestrous cycle length of 19-21 days and clear uterine discharge during oestrus were selected for this experiment during breeding season (March-August). All the mares were randomly divided into 3 groups. Group $1(n=10)$ mares were treated with PG and HcG based protocol. The ovarian status of each mare was detected by ultrasonography. Mares having mature corpus luteum (CL) and medium size $(20 \mathrm{~mm}-24 \mathrm{~mm})$ growing follicle (day 1) were injected with Estrumate (cloprostanol sodium $500 \mu \mathrm{g}) 2 \mathrm{ml}$ intramuscularly on day 1 morning and then on $6^{\text {th }}$ day morning mares were administrated with injection Chorulon 3000 I.U. intravenously. After that on day 14 mares were again injected with Estrumate $2 \mathrm{ml}$ intramuscularly followed by injection Chorulon 3000 I.U. intravenously on $20^{\text {th }}$ day morning. All mares in group 1 were allowed for $1^{\text {st }}$ covering after 12 hours of last Chorulon injection followed by second covering at 36 hours interval. In group $2(\mathrm{n}=10)$ mares were injected with single injection of Estrumate $2 \mathrm{ml}$ intramuscularly after detection of mature CL and medium size growing follicles (20-24 mm) by ultrasonography. In group $3(\mathrm{n}=5)$ mares were covered at 3-5 day of natural oestrus.

Mares in all the groups were allowed to covering twice at 36 hours interval after detection of clinical oestrus signs, teasing score and the size of dominant follicle ( $\geq 30 \mathrm{~mm}$ ) by ultrasonography (easi-scan BCF technology linear array tranducer) regularly on alternate days to monitor the size of dominant follicle and to access the ovulation after 24 hours of $2^{\text {nd }}$ covering. Pregnancy was diagnosed after 30 days from last covering in all the groups.

Table 1: Evaluation of mare's oestrus by Teasing Score System

\begin{tabular}{ll}
\hline $\begin{array}{l}\text { Teasing } \\
\text { score }\end{array}$ & Behavioral response of mare towards stallion \\
\hline 0 & $\begin{array}{l}\text { Mare shows no sign of receptivity, possibly some } \\
\text { aggression towards stallion, striking, ear back, } \\
\text { kicking, squealing etc. }\end{array}$ \\
1 & $\begin{array}{l}\text { No aggression toward the stallion. } \\
\text { some interest mare may approach the stallion and } \\
\text { exhibit some winking of the vulva and tail raising } \\
2\end{array}$ \\
$\begin{array}{l}\text { More interest, tail raising, squatting, urination. } \\
\text { Intense interest, turns hind quarters towards the } \\
\text { stallion with continuous winking and frequent } \\
\text { urination. }\end{array}$ \\
\hline
\end{tabular}

Source: Coleman, B. and Powell D. 2020. University of Kentucky. USA.

The numerical data regarding dominant size of follicle, duration of estrus, ovulation rates and conception was represented as Mean \pm SEM and difference were considered to be significant at $\mathrm{P}<0.05$. The data was statistically analyzed for significant value by using students t-test and chi square test

\section{RESULTS AND DISCUSSION}

In group $1(\mathrm{n}=10)$ mares oestrous cycle was artificially controlled during breeding season (March - August). The mature corpus luteum on either side of ovary serves as a source of progesterone. On day 1 after detection of mature CL by ultrasonography, injection prostaglandins (PGF2 $\alpha$ ) $2 \mathrm{ml} \mathrm{I} / \mathrm{m}$ was administered to bring luteolysis 
of mature CL which results in decrease of progesterone concentrations. The prostaglandins injection is quite effective to cause lysis of CL after 5-6 days of subsequent ovulation in mares and mares return to oestrus after 3660 hours of PGs administration (Norman and Larsen, 2010). PGs injection on day 1 morning results in lysis of $\mathrm{CL}$ in $80 \%$ of mares and the follicles start developing at subsequent ovary. On day $6^{\text {th }}$ injection chorulon 3000 I.U. intravenously resulted into ovulation of $70 \%$ of mares. The first set of PGs and chorulon was effective to remove the CL and to ensure ovulation of dominant follicle. After the ovulation during $1^{\text {st }}$ regimen leads to proper formation of $\mathrm{CL}$ for the next cycle. Immature corpus luteum requires 5 or more days in maturation and becoming responsive to prostaglandin injection again. Kelleman (2013) postulated that the functional development of CL is attained after 5 days of previous ovulation and it secretes progesterone of concentration upto $4 \mathrm{ng} / \mathrm{ml}$. In group 1 mares from the $14^{\text {th }}$ day morning onwards the second regimen (PGs and chorulon) starts with injection prostaglandins $2 \mathrm{ml}$ intramuscularly which leads to ensured lysis to mature $\mathrm{CL}$ formed after the ovulation during $1^{\text {st }}$ regimen. The mares will return to oestrus within 48-72 hours post PGs injection. Similar observations were also reported by Larson (2013) that shows single injection of prostaglandins during diestrus results in induction of luteolysis within 2448 hours and mares will return to oestrus within 2-4 days. The clinical signs of oestrus in mares (70\%) were observed during day 3-4 post PG administration, like winking of clitoris, frequent urination in response to teasing, tail raising, squatting etc. All the mares during $2^{\text {nd }}$ regimen were examined to detect the dominant follicle size by ultrasonography on alternate days, followed by injection chorulon 3000 I.U. intravenously on $20^{\text {th }}$ day morning and then all mares were allowed to $1^{\text {st }}$ covering after 12 hours. The second covering of all mares was done after 36 hours interval from $1^{\text {st }}$ covering. After 24 hours of last covering the mares were examined by ultrasonography for the confirmation of ovulation, which revealed that successful ovulation occurred in $90 \%(9 / 10)$ of mares. The mean \pm SEM diameter of dominant follicle was $33.2 \pm 0.2 \mathrm{~mm}$. Urquieta et al. (2009) reported that the administration of Chorulon 2500 I.U. intravenously results in ovulation of mature dominant follicle within $36-48$ hours. The mean \pm SEM $(\mathrm{P}<0.05)$ of duration of oestrus in group 1 mares was $6.9 \pm 0.1$ days. (Bucca and Carli, 2011) concluded that after the chorulon (2500 I.U.) injection $90.9 \%$ of the mares were successfully ovulated within 36-48 hours. According to (Raz et al., 2010) the ovulation rate of mares after chorulon injection was $73 \%$. Pregnancy diagnosis of group 1 mares was done on day $30^{\text {th }}$ from last covering revealed 70\% (7/10) conception rate. (Cuervo-Arango and Newcombe, 2008) reported that $75 \%$ of ovulated mares conceived by using particular hormonal protocol based upon PGs and chorulon. Figueiredo (2011) concluded that the mares treated with chorulon based hormonal regimen results in ovulation within 45.6 hours and pregnancy rates were $75 \%$.

In group $2(n=10)$ after detection of mature corpus luteum by ultrasonography mares were administered with single injection of prostaglandin (estrumate) $2 \mathrm{ml}$ intramuscularly. This resulted into complete lysis of CL in $70 \%$ of mares and observed clinical signs of oestrus within 3-4 days. (Potter, 2017) observed that mares after treatment with PGs come to oestrus within 3-5 days. Administration of prostaglandins during diestrus results into luteolysis within 24-48 hours and mares will returns to oestrus within 2-3 days (Larson, 2013). Mares in group 2 were allowed to cover after observing clinical oestrus signs, teasing score and size of dominant follicle detected by ultrasonography twice at 36 hours interval. The ovulation rate in this group was $80 \%$ and the Mean \pm SEM of diameter of dominant follicle was $31.6 \pm 0.2 \mathrm{~mm}$ with average duration of oestrus $7.4 \pm 0.2$ days. (Card, 2011; Sertich 2020) reported that after prostaglandin induced mares comes to oestrus within 3 days however, the timing of ovulation may vary from 3-10 days. The conception rate in this group was $60 \%(6 / 10)$.

Tables 2: The results of selected parameters in different groups

\begin{tabular}{lllll}
\hline $\begin{array}{l}\text { Sl. No. } \\
\text { Parameters } \\
\text { (Mean } \pm \text { SEM) }\end{array}$ & Group 1 & Group 2 & Group 3 \\
\hline 1 & Oestrus duration (Days) & $6.9 \pm 0.1$ & $7.4 \pm 0.2$ & $7.9 \pm 0.1$ \\
2 & $\begin{array}{l}\text { Size of dominant follicle } \\
(\mathrm{mm})\end{array}$ & $33.2 \pm 0.2$ & $31.6 \pm 0.2$ & $30.8 \pm 0.2$ \\
& Ovulation rates (\%) & $90(9 / 10)^{\mathrm{a}}$ & $80(8 / 10)^{\mathrm{b}}$ & $60(3 / 5)^{\mathrm{b}}$ \\
3 & Pregnancy rates (\%) & $70(7 / 10)$ & $60(6 / 10)$ & $60(3 / 5)$ \\
\hline
\end{tabular}

a b Significant at $\mathrm{P}<0.05$.

In group $3(n=5)$ the mares with natural oestrus were covered twice at 36 hours after detection of size of dominant follicle, clinical oestrus signs and teasing 


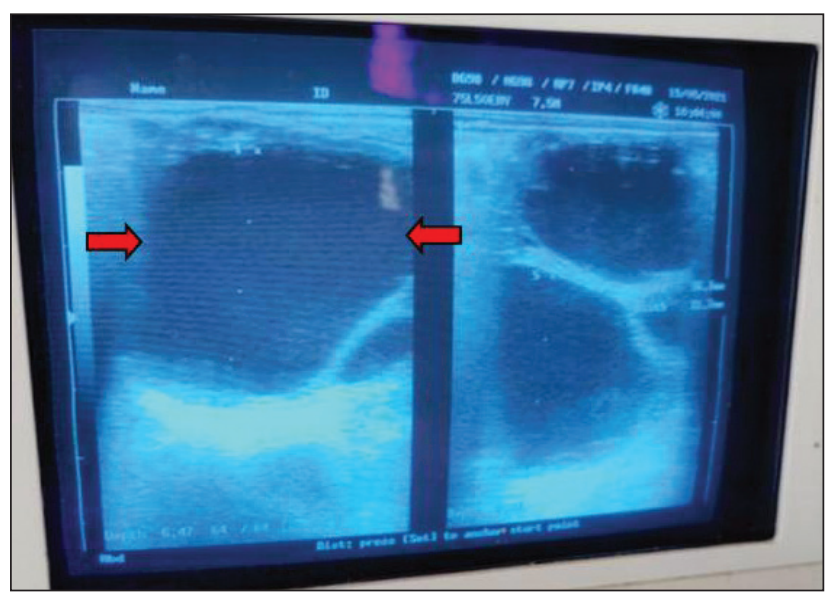

Fig. 1: Mature dominant follicle $\geq 30 \mathrm{~mm}$ diameter

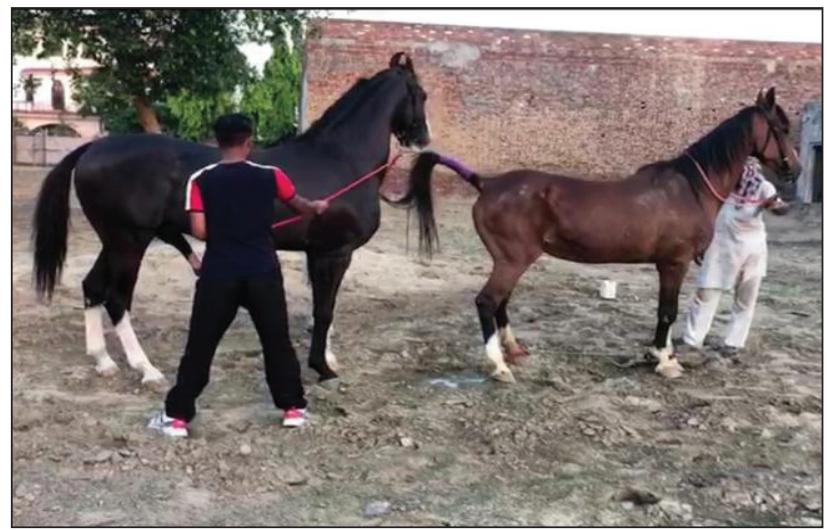

Fig. 3: Clinical oestrus signs observed in mare after hormona treatment

score. In this group $60 \%$ of mares successfully ovulated, with $30.8 \pm 0.2 \mathrm{~mm}$ (Mean \pm SEM) diameter of dominant follicle. The average (Mean \pm SEM) duration of oestrus in this group was $7.9 \pm 0.1$ and overall pregnancy rate in group 3 was $60 \%(3 / 5)$.

\section{CONCLUSION}

The use of exogenous hormones is not very much trending among stud farms of Punjab. The farmers are unaware for the application of hormonal regimens for oestrus synchronization in mares. In tropical regions during the breeding season (March to August) there is a lot of variation in dominant size follicle, ovulation rates and duration of oestrus among the Marwari mares. In this study the duration of oestrus, ovulation and conception rates were improved with the application of exogenous hormones

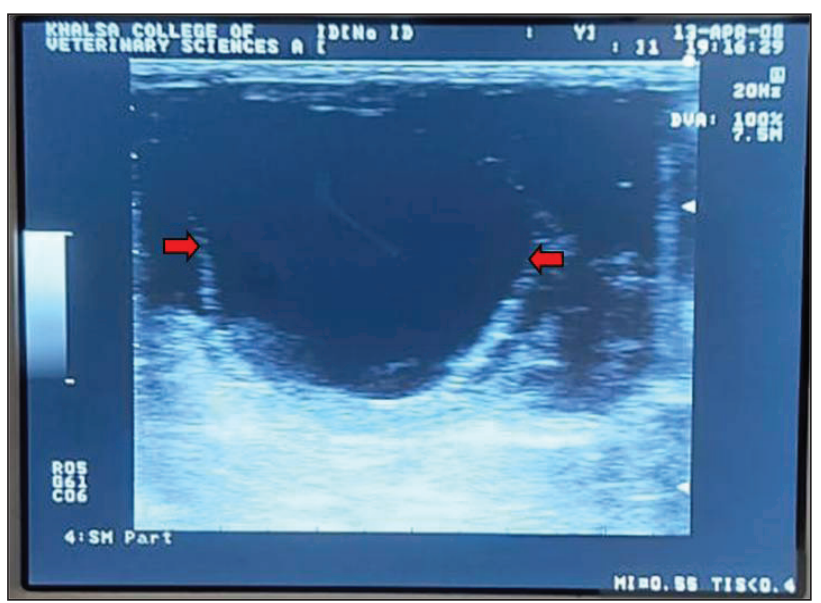

Fig. 2: Ovulating follicle $\geq 35 \mathrm{~mm}$ diameter

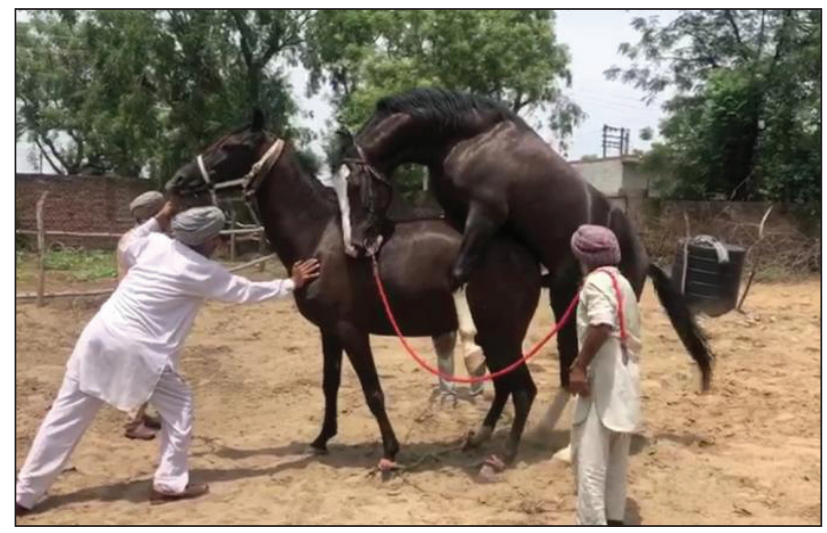

Fig. 4: Covering of mare after detection of dominant follicle

for oestrus synchronization in group 1 as compared to other groups. It was seen that the ovulation rates were significantly higher in group 1 treated with the PG and $\mathrm{HcG}$ combination. There was no significant difference between the size of dominant follicle and conception rates in all groups. This study concluded that the use to exogenous hormones is quite helpful in synchronization of estrus and timely ovulation in mares which increases the chances of conception during breeding season. This results in a successful breeding season, as it reduces the rearing and management cost for stud farm owner.

\section{REFERENCES}

Bucca, S. and Carli, A. 2011. Efficacy of human chorionic gonadotropin to induce ovulation in the mare, when associated with a single dose of dexamethasone administered 
at breeding time. Equine Vet. J., 43(40): 32-34.

Card, C. 2011. Hormonal management of mares. Proceedings fetch DVM 360 conference, Kansascity, Baltimore, San Diego, USA.

Coleman, B. and Powell, D. 2020. Teasing Mares. Cooperative Extension. University of Kentucky. USA.

Cuervo-Arango, J. and Newcombe, J.R. 2008. Repeatability of preovulatory follicular diameter and uterine edema pattern in two consecutive cycles in the mare and how they are influenced by ovulation inductors. Theriogenology, 69(6): 681-87.

Evans, P. 2010. Body Condition Scoring: A management tool for evaluating all horses. Cooperative extension. Utah State University. USA.

Figueiredo, T., Paiva, R., Kozicki L.E., Kaercher, F., Weiss, R.R., Santos, I.W.D. and Muradas, P.R. 2011. Induction of ovulation in quarter horse mares through the use of deslorelin acetate and human chorionic gonadotrophin (hCG). Braz. Arch. Biol. Technol., 54(3): 517-521.

Kelleman, A.A. 2013. Equine pregnancy and clinical applied physiology. American Association of Equine Practitioners Proceeding. College of veterinary medicine, Gaineaville, Florida, USA. 59: 350-53.

Larson, E. 2013. Prostaglandins for controlling mares' estrous cycle. Act symposium. Society for Theriogenology
Conference. Louisville, Kentucky, USA.

McCue, P.M. 2010. Foal heat breeding. Equine Reproduction Labatory. Colorado State University, USA.

Norman, S.T. and Larsen, J.E. 2010. The synchronization of oestrus and ovulation in the mare. Rural Industries Research and Development Corporation. http:/www.rirdc.gov.au. Australian Government. 10: 202.

Potter, M.K. 2017. Comparison of serial PGF2 $\alpha$ protocols for control of the estrous cycle in mares. Bear Works Masters Theses. Graduate college, Missouri State University, USA. http:/bearworks.missouristate.edu/theses /3155.

Raz, T., Amorim, M.D., Stover, B.B. and Card, C.E. 2010. Ovulation, pregnancy rate and early embryonic development in vernal transitional mares treated with equine- or porcine FSH. Reprod. Domest. Anim., 45(2): 287-94.

Sertich, P.L. 2020. Reproductive cycles in horses. The Merck Veterinary Manual. New balton center, School of veterinary medicine, University of pennysylvania, USA.

Urquieta, B., Duran, M.C., Coloma, I. and Parraguez, V.H. 2009. hCG - induced ovulation in thoroughbred mares does not affect corpus luteum development and function during early pregnancy. Reprod. Domest. Anim., 44(6): 859-64.

Vidauri, C.Z., Flores, A.C., Delgado, R.M., Berumen, R.F., Carlos, L.M. and Flores, F.G. 2018. Mare reproductive cycle: A review. Abanico Vet. 8(3): 14-41. 
